\title{
Does State Repression Spark Protests? Evidence from Secret Police Surveillance in Communist Poland
}

\author{
ANSELM HAGER Humboldt-Universität zu Berlin, Germany \\ KRZYSZTOF KRAKOWSKI Collegio Carlo Alberto, Italy
}

\begin{abstract}
$D$ oes physical surveillance hinder or foster antiregime resistance? A common view holds that surveillance prevents resistance by providing regimes with high-quality intelligence on dissident networks and by instilling fear in citizens. We contrast this view using formerly classified data from Communist Poland. We find that communities exposed to secret police officers were more likely to organize protests but also engaged in less sabotage. To ensure that the relationship is causal, we use an instrumental variable strategy, which exploits the exogenous assignment of Catholic "spy priests" to local communities. To trace the underlying mechanisms, we draw on qualitative interviews and archival sources. We document that Poland's comprehensive use of surveillance created widespread anger as well as an incentive for citizens to reveal their true loyalties, thus facilitating antiregime collective action. Once on the streets, protesters refrained from sabotage to signal their political motivation to bystanders and authorities alike.
\end{abstract}

\section{INTRODUCTION}

A

uthoritarian regimes around the globe use repression to secure their survival. Much has been written about violent forms of repression. ${ }^{1}$ We know comparatively little, however, about nonviolent forms of repression. While there is growing interest in digital monitoring (Gohdes 2020; King, Pan, and Roberts 2013; Xu 2020), we lack systematic accounts that explore whether physical surveillance affects antiregime resistance (Davenport 2005). By physical surveillance, we mean "focused, systematic, and routine attention to personal details for purposes of influence, management, protection or direction" (Lyon 2007, 13). The dearth of evidence is surprising, given that physical surveillance constitutes one of the most consistently used measures of repression (Shelley 1996). Particularly in the former Eastern Bloc, regimes employed tens of thousands of agents to systematically spy on citizens (Gläßel and Paula 2019; Lichter, Löffler, and Siegloch 2021).

Existing research on physical surveillance suggests that it is an effective tool for muting resistance. For one, surveillance arguably instills fear in the population and thus reduces individuals' propensity to dissent. Surveillance also enables the regime to collect high-quality

Anselm Hager (D), Assistant Professor of International Politics, Institute for Social Sciences, Humboldt-Universität zu Berlin, Germany, anselm.hager@hu-berlin.de.

Krzysztof Krakowski (D), Assistant Professor of Political Science, Collegio Carlo Alberto, Italy, and Research Fellow, Department of Politics, Culture, and Society, University of Turin, Italy, krzysztof. krakowski@carloalberto.org.

Received: May 05, 2020; revised: January 20, 2021; accepted: June 23, 2021. First published online: September 14, 2021.

${ }^{1}$ E.g, Balcells, Dorsey, and Tellez (2020), Carey (2006), Rozenas, Schutte, and Zhukov (2017), and Zhukov (2019). information and thereby effectively combat antiregime collective action. While theoretically persuasive, we contend that there are two rivaling channels, which have received comparatively less scholarly attention. At the individual level, surveillance can engender anger, partly because it is a constant threat and partly because it can be humiliating. At the group level, surveillance can provide citizens with an incentive to reveal their true loyalties given widespread social mistrust, thus facilitating antiregime collective action. Both channels imply that surveillance can backfire and spark antiregime resistance.

To explore these conjectures empirically, this article studies Communist Poland-an authoritarian regime that instituted a far-reaching surveillance network to repress its citizens. We track the regime's espionage activities by drawing on formerly classified records of secret police officers, which provide a unique lens into the mechanics of physical surveillance at the local level. Our outcomes are previously untapped data on antiregime protests organized by the Solidarność trade union. In addition, we measure individual acts of resistance using data on noncompliance with voluntary Saturday work - our proxy for sabotage. Our empirical focus is the Upper Silesia region, which is not only representative of Poland but also affords rich microlevel data on surveillance and antiregime resistance. Importantly, the data span the entire period from 1945 to 1989 , offering an unparalleled glimpse into the shortand long-term effects of physical surveillance in an authoritarian regime.

Using two-way fixed-effect panel models, we find that an additional secret police officer in a local community is associated with a 0.09 standard deviation (henceforth, $\mathrm{SD})$ increase in protests and a $0.07 \mathrm{SD}$ reduction in sabotage. The results are robust to (i) controlling for likely confounders, (ii) adjusting for spatial autocorrelation, (iii) using a geographic matching design, and (iv) conducting a randomization inference procedure. To probe whether the relationship is causal, we propose 
an instrumental variable strategy. In the early days of the regime, the secret police's ability to surveil citizens depended critically on the cooperation of the Catholic Church. In some communities, the secret police managed to corrupt priests who then spied on citizens and recruited additional informants (Nalepa and Pop-Eleches 2019). In other communities, the secret police failed to corrupt priests. Importantly, the corruptibility of priests was plausibly exogenous: priests were sent to municipalities by the Catholic Church, often when another priest had retired. Using two-stage least squares regressions, we confirm that surveillance, instrumented with corrupted priests, increased protests while lowering sabotage.

What mechanisms give rise to the observed findings? Based on qualitative data, we point to two channels that link surveillance to protests. First, surveillance created widespread anger. Notably, when analyzing 62 dissident testimonies we show that "anger" is the most predictive emotion of surveillance-related terms. Second, surveillance provided citizens with an incentive to reveal their true loyalties given widespread social mistrust. In one testimony, for example, a dissident countered suspicions that he was a spy by going on a public hunger strike. The reduction in sabotage, in turn, was arguably the product of protest dynamics. Using archival sources, we show that dissident groups, including Solidarność chapters, assured that its members did not engage in any illegal acts of sabotage or vandalism so as to give the regime no pretext to violently intervene.

Our article makes three contributions to the study of repression in authoritarian regimes. First, we explore an understudied but widely used form of repression: physical surveillance (Cunningham 2003; Davenport 2005; Marx 1988). Our results demonstrate that surveillance is an ambivalent repressive tool: surveillance sparks protests but reduces sabotage. Importantly, the evidence comes from a typical case in the Eastern Bloc and relies on administrative data spanning over 40 years coupled with plausible causal identification. The setting thus affords reliable internal and external validity. Second and relatedly, we provide novel theoretical mechanisms that explain these ambivalent effects. Based on qualitative data, we show that surveillance created widespread anger and gave citizens an incentive to reveal their true loyalties amid rampant social mistrust, thus facilitating protests (Kuran 1997). Once on the streets, citizens then refrained from sabotage to underscore the legality of their protests. Third, our findings raise the question of whether the influential substitution hypothesis by Lichbach (1987) and Scott (1985) - that is, the idea that repression prevents protests while sparking sabotage-may have the direction of strategic substitutability upside down, at least in the context of surveillance.

\section{SURVEILLANCE AND RESISTANCE}

This paper studies the link from physical surveillance to antiregime resistance. Research on surveillance is a vibrant field across the social sciences, ${ }^{2}$ and some

\footnotetext{
${ }^{2}$ See, e.g., Davenport (2005), Donner (1980), and Marx (1988).
}

authors even speak of a field of surveillance studies (Fuchs 2013). Physical surveillance includes numerous techniques: the following and monitoring of targets, opening correspondence, eavesdropping, and use of informants. Therefore, surveillance constitutes a distinct form of state repression compared with alternative nonviolent forms of repression such as detentions (Truex 2019), censorship (Gläßel and Paula 2019), or internet restrictions (Gohdes 2020).

Does surveillance foster or hinder antiregime resistance? While research on the effects of surveillance on resistance remains scarce, to our knowledge the majority of published studies make the case that surveillance effectively reduces resistance. Two core mechanisms undergird this effect. The first channel operates at the individual level: surveillance instills fear in the population and thus reduces individuals' propensity to dissent. The second channel operates at the group level: surveillance enables a regime to effectively mute antiregime collective action. We lay out both channels in turn. Afterwards, we introduce two alternative predictions whereby surveillance can increase antiregime resistance: at the individual level, surveillance can engender anger, and at the group level surveillance can provide incentives to citizens to reveal their true loyalties and thus facilitate antiregime collective action.

\section{Surveillance as a Deterrent of Resistance}

\section{Individual Level: Surveillance May Instill Fear}

The first mechanism through which surveillance may deter antiregime resistance is by creating fear, which may in turn reduce individuals' propensity to dissent. Physical surveillance is conducted in secret. Yet, communities seldom fail to learn that they are being spied on (Gross 2002). This happens, inter alia, through the spread of rumors (Blaydes 2018, 201) and due to mistakes committed by regime agents. The resulting uncertainty-one never quite knows whether one is being surveilled-arguably creates fear. For instance, Starr et al. $(2008,259)$ in their qualitative study of social justice organizations in the United States write, "a goal of [surveillance] is to isolate the movements that are being repressed, using the fear of millions of people to create that political isolation." In our own study context, Eugeniusz Gatnar, a notable antiregime activist, recalls a constant fear of being monitored: "I knew that the SB [secret police] was following me. I always told myself: don't cross the street on a red light, validate tickets in the tram"3 (Kurpierz 2012, 266). Dissident Barbara Kozłowska adds: "Many people did not want to read the underground press because they were afraid. [Surveillance] was a typical psychological harassment; it created an atmosphere of tension and fear." ${ }^{4}$ Fear, in turn, may preclude individuals from voicing dissent. Young (2019), for instance, demonstrates that fear figures prominently in the tactical

\footnotetext{
${ }^{3}$ All translations from Polish are our own.

${ }^{4}$ Archival interview on 11/23/2005.
} 
repertoire of authoritarian regimes, partly because it makes individuals risk averse. Taken together, surveillance-by instilling fear in the population-may thus lower both individual as well as collective forms of resistance.

- H1: Surveillance decreases individual and collective resistance by instilling fear.

\section{Group Level: Surveillance May Raise Collective Action Costs}

A second mechanism through which surveillance may deter antiregime resistance is by raising the cost of collective action. Three arguments undergird this conjecture. First, surveillance allows the government to obtain high-quality information on dissident activities (Sullivan 2016). Information obtained through surveillance can then be used to neutralize key players within opposition groups (Nalepa and Pop-Eleches 2019) and avoid costly co-option (Xu 2020). Second, surveillance allows the government to effectively perturb information flows within dissident networks. Cunningham, for instance, cites a memo about the Federal Bureau of Investigation's surveillance of the New Left in the 1960s, which called on agents to "devise methods of utilizing the disorganization [created by surveillance] to prevent the New Left from becoming active" (2003, 229). Third, surveillance creates an atmosphere of suspicion (cf. Hager, Krakowski, and Schaub 2019). Lichter, Löffler, and Siegloch (2021), for example, find that surveillance in East Germany reduced trust toward other citizens. Trust, in turn, is a crucial ingredient for facilitating antiregime collective action (Parkinson 2013, 423). In our study context, one dissident recalls: "It became clear that we were under full observation. One has to realize that this weakened any opposition." 5 Taken together, one may therefore expect that surveillanceby raising the cost of collective action-reduces collective forms of resistance. The effect on individual forms of resistance, however, is less clear. In fact, several authors argue that repression (here, surveillance) that undercuts collective action leads individuals to substitute their energy toward individual resistance (Lichbach 1987).

- H2: Surveillance decreases collective resistance by raising the transaction costs of collective action and thus leads citizens to engage in individual resistance.

\section{Surveillance as a Cause of Resistance}

\section{Individual Level: Surveillance May Create Anger}

While fear is a plausible product of surveillance, we contend that there is a rivaling individual-level mechanism: surveillance can cause anger, which may increase individuals' propensity to dissent. Two arguments undergird the prediction that surveillance causes anger. First, surveillance is a constant threat (we provide

\footnotetext{
${ }^{5}$ Own interview on 12/22/2020.
}

evidence for this claim in the Generalizability section). And, as noted by Gurr, "if men are exposed to noxious stimuli that they cannot avoid or overcome, they have an innate disposition to strike out at their sources" (1970,22-23). Second, surveillance is a comprehensive, intrusive form of repression, which often violates citizens' privacy. Surveillance thus maps onto Scott's typology of domination and resistance, which stipulates that humiliating forms of repression engender anger (Scott 1989, 56). Evidence that surveillance causes anger is, inter alia, provided in Gary Marx's seminal book on surveillance in the U.S. He writes, "I was shocked and angered that a peaceful democratic organization dedicated to ending racial discrimination could be a target of such police action," by which he refers to surveillance (Marx 1988, xvii). If surveillance creates anger, the link to resistance is rather short. Several social movement scholars, for instance, have pointed to a possible connection between surveillancerelated anger and the emergence of more violent protests (Della Porta 2006; Earl 2011). In our own context, Leopold Tyrmand, a known opposition writer in Communist Poland, observed, "The fact that [a secret police officer] has a thick pile of testimony files on his desk and that he knows better than I remember what I was doing in November [...] was highly mobilizing" (1983, 173). Taken together, surveillance may thus create anger, which may lead individuals to resist the regime both individually and collectively.

- H3: Surveillance increases individual and collective resistance by causing anger.

Group Level: Surveillance May Create Incentive to Reveal Loyalties

A second rivaling mechanism through which surveillance may spark antiregime resistance is by giving citizens an incentive to reveal their true loyalties, thus facilitating collective action. Recall that even if surveillance creates an individual-level impetus to dissent (via the aforementioned anger-release mechanism), dissident groups must still solve stark collective action problems. One way to solve such problems is to incentivize the truthful revelation of citizens' loyalties, starting with the most committed antiregime dissident (Kuran 1997). Surveillance arguably provides such an incentive. In Poland, the widespread use of informers meant surveillance was performed by close acquaintances or even relatives. As a result, everyone could potentially be suspected of being a regime collaborator. As much is illustrated in the memoirs of Leopold Tyrmand who was falsely suspected of spying for the secret police: "Whoever I talked to, I searched in their eyes for a hidden caution. [...] I tracked down the distrust of others, sniffed for their reticence, defensive falsehood, suspicion directed against me" $(1983,284)$. In such a situation, citizens, like Tyrmand, have a formidable incentive to reveal their true loyalties in order to reap the reward of not being viewed as a spy. Taken together, surveillanceby instilling mutual mistrust among friends, neighbors, and colleagues-gives potential dissidents an 
incentive to reveal their true loyalties, thus facilitating collective action. And the most credible signal of one's loyalties was undoubtedly to resist - either at the collective or individual level.

- H4: Surveillance increases individual and collective resistance by providing incentives to reveal one's true loyalties.

\section{Scope Conditions}

We have spelled out conflicting theoretical mechanisms how physical surveillance can affect individual and collective resistance. Several words of caution are in order, however. First, the degree to which the four channels are activated hinges critically on the nature of surveillance. Brief and targeted surveillance arguably engenders different effects-including on the aforementioned mechanisms-compared with enduring and comprehensive forms of surveillance. We revisit the issue of scope conditions in the Generalizability section, inter alia, by characterizing surveillance across the globe. Second, the mechanisms need not operate uniformly in the population. For example, it could be that some individuals become afraid but others become angered due to surveillance. We discuss this issue in the Mechanisms section by drawing on individual-level survey evidence. Third, the mechanisms are not collectively exhaustive; they merely capture our reading of the published literature. What is more, the proposed channels are undoubtedly shaped by our knowledge of the Polish case. We revisit this issue in the External validity subsection. Last, the channels are not unique to surveillance. Anger, for example, can be instilled by a diverse set of repressive tactics. We merely contend that anger is one plausible product of surveillance.

\section{DESIGN}

\section{Historic Background}

To explore the influence of surveillance on individual and collective forms of resistance, we study Communist Poland (a more detailed historic background is provided in Online Appendix A.1). Following World War II, in 1947 the Soviet Union imposed a Marxist-Leninist government in Poland, called the Polish People's Republic (henceforth, PPR). Life in the PPR represented a constant struggle to make ends meet, and over the years Poles grew increasingly frustrated with the regime. To avert open resistance, the PPR established the Department of Security (Urzad Bezpieczeństwa, UB; since 1956 Służba Bezpieczeństwa, SB), a secret police and espionage agency. The secret police hired an extensive network of informants, including Catholic priests (more below), who reported on neighbors and work colleagues. Agents, inter alia, surveilled points of interest, followed suspected individuals, and read citizens' correspondence. Despite the extensive surveillance measures, Polish citizens did not cease to resist. Sabotage was a common occurrence in state firms and large-scale protests began as early as the mid-1950s. By the early 1980s, protests organized by workers of state firms led to the creation of the Independent and Self-Governing Trade Union Solidarity (henceforth, Solidarność), the first independent trade union in Communist Poland. Solidarność created a broad, nonviolent, anticommunist social movement. The following years saw bitter fights, and the PPR was ultimately forced to hold (semi-)free elections in 1989. A Solidarność-led coalition won by a large margin, paving the way for Poland's democratic transformation.

\section{Case}

To explore whether the regime's extensive surveillance measures were effective, we draw on micro-level data from Upper Silesia, which lies in southern Poland (see Figure 1). Our study thus takes the form of a case study, which allows us to provide rich contextual evidence on how repression interacts with resistance in one setting (e.g., Brockett 1993; Loveman 1998; Thompson 2007). We also join a small, but growing number of studies that explore historical cases of uprisings (e.g., Einwohner 2003). Importantly, our case study can only trace the effects of surveillance on resistance in one setting with one set of scope conditions. To address aggregate-level studies (e.g., Fariss 2019), the Generalizability section provides data where our case falls in the broader universe of countries that use surveillance.

Upper Silesia has 297 municipalities of which 71 are cities and 226 are rural communities. We focus on Upper Silesia for two reasons. First, Upper Silesia is the only region in Poland that affords rich, formerly classified micro-level data on surveillance measures and resistance. Other parts of Poland only report the incidence of surveillance at more aggregate levels. Second, Upper Silesia arguably affords a high degree of generalizability. The region is representative of Poland in terms of demography, wealth, industry, and urbanization (see Table A.18 in the Online Appendix). Importantly, within Poland, Upper Silesia also represents a "typical case" with respect to the size of surveillance networks and popular membership in the antiregime protest movement, Solidarność (see Table A.18). From 1975 to $1984,14.4 \%$ of all secret police agents operated in Upper Silesia, a region that accounted for $17.5 \%$ of the Polish population. In 1981, 26.1\% of Upper Silesians were members of Solidarność compared with $26.5 \%$ in all of Poland (Lewandowska 2021).

\section{Measurement}

\section{Physical Surveillance}

We measure physical surveillance using heretofore untapped data on the number of secret police officers in municipalities in Upper Silesia from 1945 to 1989. To obtain these data, we digitized archival sources from the Institute of National Remembrance (IPN, Polish acronym), which lists all secret police officers who operated in the region. As we outline below, the secret 


\section{FIGURE 1. Surveillance in Upper Silesia}

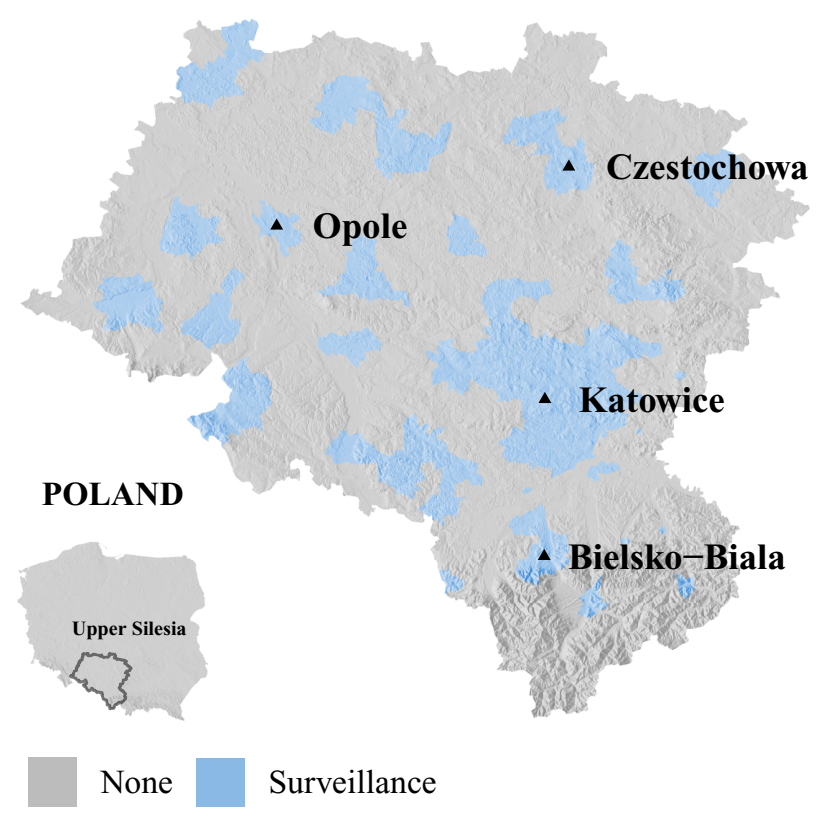

Note: The map shows all Upper Silesian municipalities exposed to any secret police officers between 1945 and 1989.

police was charged with a variety of surveillance tasks. The resulting variable, Surveillance, indicates the number of officers per year and municipality from 1945 to 1989. Out of 297 localities, 49 had at least one officer between 1945 and 1989 (see Table A.1 in the Online Appendix). Reassuringly, the map in Figure 1 shows sustained geographic variation, alleviating concerns about spatial autocorrelation. ${ }^{6}$

While the data do not cover all agents of the secret police, the number of officers is a good proxy for the overall number of agents and spies. For one, officers were specifically instructed to recruit additional informants. What is more, the officers were tasked with monitoring the broader intelligence network of all rank-and-file agents and informants. Still, to quantitatively corroborate that the number of officers predicts secret police personnel overall, we digitized data on all UB staff (including agents and informants) from 1945 to 1956 in 23 municipalities for which this data is available. Table A. 2 shows that the number of officers strongly predicts the number of UB personnel even when including time and locality fixed effects.

\section{Protests}

We measure antiregime protests by geocoding all Solidarność strikes from 1980 to 1986 (Table A.1). Four

\footnotetext{
${ }^{6}$ One empirical concern is that secret police officers may also have surveilled neighboring municipalities (or, for that matter, not have engaged in any surveillance). Such spillover, however, would likely dampen any treatment effects. The effect of surveillance, which we estimate below, was thus likely higher, though we have no data on how widespread potential spillover or shirking on behalf of secret police agents was.
}

reasons make the strikes a particularly relevant outcome. First and most important, Solidarność ultimately led to the toppling of the PPR. Tracing the determinants of the strikes is thus highly relevant if we are to understand repression and regime survival more broadly. Second, while there were other uprisings, Solidarność strikes showed pronounced local-level variation. Other protests were one-off events, which does not allow for a local-level empirical design. Third and related, Solidarność strikes took place both in cities and in the countryside. The strikes also morphed into a broader social movement-a development autocratic regimes are particularly worried about. Fourth, by the 1980s, many dissident groups sought to align themselves with Solidarność, which was ideally placed to organize antiregime collective action (more in the Conclusion section). For this reason, many "protests" were organized as "strikes," partly to underline the unity of the opposition under the common Solidarność banner.

To measure Solidarność strikes, we consulted archival sources by Niezależny Samorzadny Zwiazek Zawodowy (NSZZ) Solidarność 1980-1989. We identified any mentions of strikes and included them in the dataset whenever there was information about the date and locality. Overall, we identified 276 protests in Upper Silesia, which were organized by a variety of different economic and noneconomic actors adhering to the broader Solidarność movement. ${ }^{7}$ The resulting variable, Protests, indicates the number of protests per year and municipality from 1980 to 1986 (see Table A.1). Figure 2 shows the geographical distribution of protests, showcasing pronounced geographic variation.

\footnotetext{
${ }^{7}$ Further details on the strikes/protests are provided in Online Appendix A.2.
} 


\section{FIGURE 2. Protests in Upper Silesia}

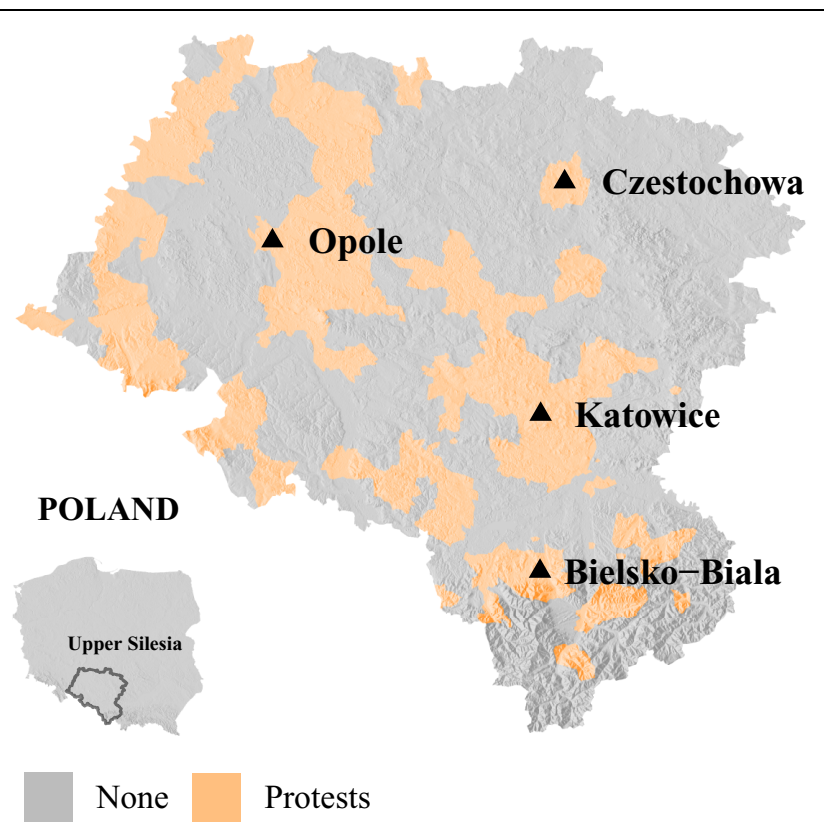

Note: The map shows all Upper Silesian municipalities where any Solidarność strike took place between 1980 and 1986.

\section{Sabotage}

To measure individual-level acts of resistance, we collected data on citizens' attendance at voluntary Saturday work - known in the Eastern Block as Subbotnik-which we gathered from Poland's statistical agency, Główny Urzad Statystyczny. Saturday work was imposed by the regime in order to compensate for economic losses due to inefficient modes of production. It also included many activities outside of work, such as cleaning public spaces. While the authorities framed Subbotnik as a voluntary contribution to socialism, in practice, it was mandatory. Community leaders and firm managers were responsible for verifying whether residents of their communities and workers of their firms contributed to Subbotnik. This was often done by circulating presence lists. Despite its mandatory character, citizens could and did sabotage Subbotnik by foot-dragging, evasion, or false compliance. Individuals regularly only signed the presence list but did not engage in any productive activity. (Further evidence that noncompliance with Subbotnik was considered a form of antiregime resistance is provided in the Mechanisms section.) Fortunately, state officials kept track of the work done during Subbotnik and its monetary value in Polish złoty (zł). This data allows us to calculate per capita Subbotnik productivity and compare it across localities. We interpret high per capita productivity as an indication of high compliance with the state initiative. Low per capita productivity, by contrast, is a likely indication of sabotage: shirking workers were not productive, the outcome of their work was thus of lower value compared with the work of compliant workers. The resulting variable, Sabotage, indicates the per capita value of Saturday work per year and municipality from 1975 to 1979 -the period in which the data were recorded. We revert and standardize the measure to accurately depict sabotage (see Table A.1).

\section{RESULTS}

\section{Panel Model}

Does physical surveillance hinder or spark antiregime resistance? To answer this question, we estimate the following panel model (simple cross-sectional models are discussed in the Robustness section below):

$$
\text { Resistance }_{i t}=\alpha_{i}+\gamma_{t}+\beta \text { Surveillance }_{i t}+\varepsilon_{i t}
$$

where Resistance ${ }_{i t}$ represents the (i) number of protests or (ii) the level of sabotage in year, $t$, in community, $i$. The variable Surveillance ${ }_{i t}$ captures the number of secret police officers in a given community and year, and $\alpha_{i}$ and $\gamma_{t}$ are community and time fixed effects, respectively. Given the use of both year and municipality fixed effects, the models thus control for any time-invariant confounders (e.g., grievances, culture, geography, ethnicity, natural resources, etc.) that shape local communities. The models also control for variables that are constant across municipalities but vary over time (e.g., political events and reforms, population levels, economic shocks, bad harvests, industrial innovations, etc.). Recall that the data for sabotage and protests are from different periods. Thus, the panel modeling protests lasts from 1980 to 1986 , while the panel modeling sabotage covers the years 1975 to 1979 . 
TABLE 1. Effect of Surveillance on Resistance

\begin{tabular}{|c|c|c|c|c|c|c|}
\hline & \multicolumn{4}{|c|}{ Protests } & \multicolumn{2}{|c|}{ Sabotage } \\
\hline & (1) & (2) & (3) & (4) & (5) & (6) \\
\hline Surveillance & $\begin{array}{c}0.092^{\star \star \star} \\
(0.004)\end{array}$ & $\begin{array}{c}0.091^{\star * *} \\
(0.004)\end{array}$ & $\begin{array}{c}0.163^{\star * *} \\
(0.012)\end{array}$ & $\begin{array}{c}0.163^{\star * *} \\
(0.012)\end{array}$ & $\begin{array}{c}-0.067^{\star \star \star} \\
(0.006)\end{array}$ & $\begin{array}{c}-0.067^{\star * *} \\
(0.006)\end{array}$ \\
\hline Year FE & No & Yes & No & Yes & No & Yes \\
\hline Locality FE & No & No & Yes & Yes & No & No \\
\hline Full $N$ & 2,079 & 2,079 & 2,079 & 2,079 & 451 & 451 \\
\hline Effective $N$ & 2,079 & 1,188 & 182 & 182 & 451 & 451 \\
\hline
\end{tabular}

To address concerns related to the time mismatch between the protest and sabotage measures, we collected additional data on protests in the 1970s (see Footnote 15), which confirm the headline findings. We standardize all outcome variables to ease interpretation. Further details on the data are provided in Hager and Krakowski (2021).

Columns 1 to 4 in Table 1 report models that gradually introduce time and municipality fixed effects, respectively. Across all years and without fitting fixed effects (Model 1), any additional secret police officer increases the likelihood for a protests occurring by 0.09 standard deviations (SD). This estimate is virtually unchanged when including year fixed effects (Model 2). When we add municipality fixed effects (Model 3), the estimate becomes, if anything, larger at 0.16 SD. When including both year and municipality fixed effects, the estimate is a similar 0.16 SD. Taken together, we thus see a positive correlation between the number of spies and protests even when controlling for all time-invariant confounders and those that vary across time but are constant across municipalities.

In Columns 5 and 6 in Table 1, we repeat the same analyses for the sabotage outcome. Here, we can only fit year fixed effects because municipality fixed effects would reduce the sample to only two communities. ${ }^{8}$ Model 5 reports the estimate across all available years. An additional secret police officer reduces sabotage by 0.07 SD. When including year fixed effects (Model 6), we continue to see a reduction by $0.07 \mathrm{SD}$, suggesting that time-varying confounders that affect communities in a similar vein are of little concern. Taken together, the models imply that secret police officers reduced sabotage in affected communities.

\section{Robustness}

Before moving to the instrumental variable model, we briefly summarize seven robustness tests, which are laid out in the Online Appendix. First, Table A.3 demonstrates that the panel models are robust to the inclusion of lags. Second, Table A.4 shows that results are

\footnotetext{
${ }^{8}$ See Table A.9 in the Online Appendix.
}

unchanged when estimating a simple ordinary least square (OLS) model (collapsing the time-series data at the municipality level). Third and perhaps most relevant, Table A.6 shows that the same OLS is virtually unchanged when adding controls for six likely confounders - wealth, state capacity, cultural diversity, colonial history, industrialization, and prior grievances - which we motivate in Online Appendix A.3.3. Fourth, we created a geographic matching design, which allows us to control for a variety of potential (unobserved) confounders and shows highly similar results (Online Appendix A.3.4). Fifth, we address concerns pertaining to spatial autocorrelation by estimating spatial error and lag models using a connectivity matrix based on adjacency and show results to be robust (Table A.8). Sixth, we conducted a randomization inference (RI) procedure by randomly assigning municipalities to secret police officers and reestimating the model presented in Table A.6 10,000 times. Figure A1 shows that the distribution of effect sizes is centered around zero, whereas the true estimate is significantly bound away from the distribution's mean (RI $p$-value of 0.015 for protests and 0.017 for sabotage). Seventh, we find that the relationship between surveillance and resistance remains unchanged once we control for the presence of overt forms of repression-namely, arrests (Table A.10).

\section{INSTRUMENTAL VARIABLE}

To probe whether the observed relationships are causal, we make use of an instrumental variable (IV) strategy. We take advantage of the fact that Poland's secret police systematically corrupted Catholic priests in the early days of the regime and turned them into spies (for an excellent analysis of the phenomenon, see Nalepa and Pop-Eleches 2019). The corrupted priests were not just highly effective informants, they also proved to be instrumental in turning other citizens into spies. Importantly, whether a given community had a priest that the regime managed to corrupt was plausibly exogenous. This is because priests were sent to municipalities by the Catholic Church, not the regime. Corrupted priests can thus serve as an exogenous predictor of why the secret police was present in some but not other 
municipalities. We lay out this argument below, but first we provide a short history of Poland's "patriot priests."

\section{A Short History of the "Patriot Priests"}

Beginning in 1946, the Polish People's Republic made a concerted effort to turn Catholic priests into agents of the secret police. The regime established a "Section for Priests within the Society of Fighters for Freedom and Democracy" (ZBOWiD, Polish acronym) whose members were referred to as "patriot priests." Corrupting Catholic priests was no easy task. Many priests had been working in communities for decades and were quintessential, much-trusted community leaders. Priests also enjoyed a high degree of autonomy, being appointed by the Vatican, not the Communist regime. A deep commitment to Christian values furthermore stood in the way of convincing priests to spy on their congregations.

To turn priests into spies, the regime relied on a variety of recruitment methods. Some priests joined voluntarily, but many needed to be compromised. To do so, the secret police systematically dug up information in order to pressure priests to act as confidants. Secret police officers focused on local parishes and specifically targeted lower-ranking clergy who were believed to be in open conflict with their superiors and bishops and/or struggled with alcoholism and mental disorders (Żurek 2009, 62). The authorities also targeted priests who had survived concentration camps or Gestapo imprisonment. The latter were expected to exhibit more positive attitudes toward the regime, which we illustrate in three exemplary biographies of corrupted priests in Online Appendix A.8.

On paper, the corrupted priests were expected to advocate for the recognition of apostolic administrators and bishops appointed by the Communist government in former German territories. Their roles quickly changed, however. Corrupted priests were specifically instructed to spy on citizens and report acts of disobedience. They were also tasked with reporting any signs of resistance that might pass unobserved by other agents of the secret police (Zurek 2009, 58). Thanks to privileged access to parishioners' households, the priests monitored whether farmers stole or underreported agriculture produce (Żurek 2009, 256-58). Corrupted priests also monitored underground Catholic student and youth organizations.

The secret police tried to make use of the priests in a covert manner so as to not arouse suspicion. This was particularly important, as the Catholic Church was known to remove corrupted priests because the Church was in firm opposition to the regime. An internal secret police manual included the following instructions:

It is better not to assign [a spy priest] to specific tasks of information gathering among the clergy, given that this work will be more difficult and the priest may reveal himself by showing too much curiosity. Agents of this type could, instead, provide precious information from their parishes, regarding such matters as networks and dens of [criminal] bands, acts of sabotage, and centers for spreading ugly propaganda. (Żurek 2009, 59)

Important for our case, corrupted priests were crucial in the regime's attempt to recruit additional spies and agents. The priests used confessions to collect compromising information on parishioners (Żurek 2009, 22, 66, 68). This included information on citizens' involvement in underground activities during World War II or instances of citizens using false names to avoid prosecution from the Communist authorities. Such information was then used by the secret police to blackmail citizens and turn them into new spies. A 1948 secret police report from Częstochowskie, for instance, notes that confessions constitute "a very psychological moment that we [the secret police] need to exploit" (Żurek 2009, 62). The effectiveness of using corrupted priests to recruit new spies can be shown in brute numbers: In the Katowickie region, for instance, within two months the secret police increased its network of informants from two individuals at the beginning of January 1952 to 14 individuals at the end of February 1952 (Żurek 2009, 61)-an increase ascribed to the large number of corrupted priests in the area.

\section{Assumptions}

To use corrupted priests as an instrumental variable for surveillance, we assume the model shown in Figure 3. Our key variable of interest is resistance, which is caused by surveillance. Surveillance and resistance, however, are arguably jointly predicted by prior grievances, to name one example for a potential confounder, which means the relationship between the two variables is not necessarily causal. Above, we have tried to rule out such confounding by including prior grievances as a control variable (Table A.6 in the Online Appendix) as well as by using a panel model, which controls for prior grievances (or any other community-level variable) by exploiting variation within communities. Yet, there may still be time-varying confounders, which we were unable to adjust for thus far.

To address this concern, we exploit the fact that the placement of Catholic priests - who were then turned into spies - is arguably exogenous. To use corrupted priests as an instrumental variable for surveillance, we must invoke five assumptions. Below, we focus on two particularly important assumptions: exogeneity and excludability. We defend the remaining assumptions - first stage, monotonicity, and stable unit treatment value assumption-in Online Appendix A.5 where we, inter alia, demonstrate a clear first stage ( $F$-statistic of 114.8).

\section{Exogeneity}

Perhaps most importantly, we must assume that the assignment of corruptible priests to local communities was, indeed, exogenous. That is, we must argue that 
FIGURE 3. Instrumental Variable Model

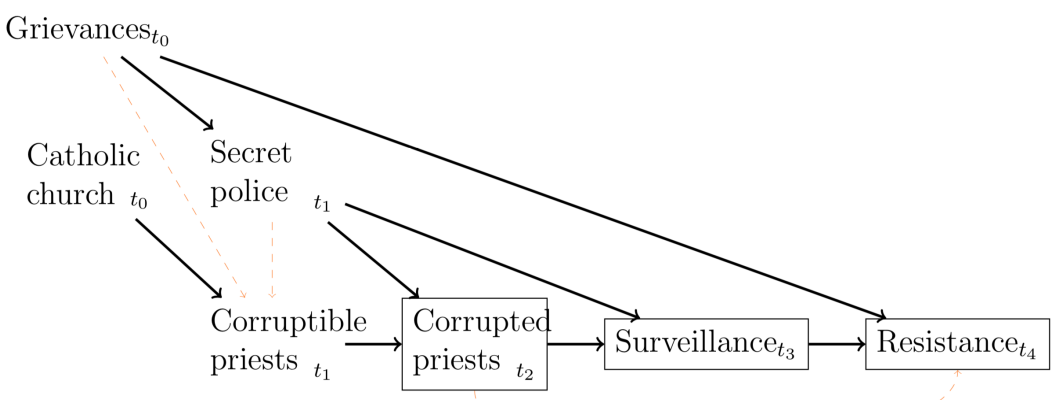

Note: Directed acyclic graph of the IV model. Solid black lines refer to causal relationships between variables at the indicated points in time. Dotted orange arrows indicate causal relations assumed to be absent.

there are no confounding variables that link corruptible priests to resistance (as Figure 3 shows). We corroborate this assumption on qualitative as well as quantitative grounds. Qualitatively, the decision about where corruptible priests were sent was made by the Catholic Church. Importantly, the Church had no reason to screen whether priests were corruptible for four reasons. First, most priests in our sample had been sent to their respective municipalities before the corruption program began. Even if the Church had wanted to support the secret police (which it did not; more details momentarily), it could not have anticipated the program before the PPR came into existence. After all, the corruption program took place in the 1950s where the vast majority of priests had already been assigned. Second, the Church's main goal in assigning priests to local municipalities was to fill vacancies. The key driver of the assignment of (corruptible) priests was thus the retirement of older priests. Third, knowledge about whether priests were corruptible was difficult to obtain. Indeed, the secret police spent hundreds of hours digging up this information. The information was thus not immediately available to the Church even if it had wanted to support the regime. Fourth and most important, there is no evidence that the Church wanted to support the regime. On the contrary, the Catholic Church was vehemently opposed to the regime's "corruption program." Whenever the Church learned that priests had been corrupted, it removed the priests, often excommunicating them (Staar 1956, 289).

One quantitative way to underline the exogeneity of the assignment of corruptible priests to local communities is to explore whether there are systematic imbalances across communities with corrupted and noncorrupted priests. A key challenge in this respect is that we do not observe whether priests were corruptible but only whether they were ultimately corrupted (we address this point in the next paragraph). We can thus only explore balance for corrupted priests. What is more, such a balance test needs to rely on data from before 1949; data after 1949 could have been affected by the presence of corrupted priests. To our knowledge, the only reliable dataset describing communities of Upper
Silesia in a comprehensive manner is the Prussian census of 1871 . The census included data on gender, education, religion, health, and migration. We digitized these data ${ }^{9}$ and then regressed the incidence of corrupted priests on all variables contained in the census. Reassuringly, Table 2 shows that not a single variable of the Census is a significant predictor of corrupted priests.

Even if the placement of corruptible priests was exogenous and despite the fact that we observe excellent pretreatment balance, two interrelated threats to inference remain. First, the government may have tried harder to obtain compromising information in certain communities-for example, those with a history of protests. Second, the government may have been more successful at obtaining compromising information in certain communities, particularly those where it already had a strong secret police presence. In both cases, communities would then not have an equal probability of being exposed to a corrupt priest-even if the assignment of corruptible priests was exogenous (indicated by the black arrow from the secret police to corrupted priests in Figure 3).

To rule out both selection mechanisms, we rely on two sources of data. First, we obtained data from secret police records on resistance prior to 1949 (see Online Appendix A.3.3). This includes data on protests, terrorist attacks, and sabotage. We then explore whether these variables predict the corruption of priests. As Table 2 shows, the variables have no explanatory power. A second piece of evidence ruling out this channel can be constructed on the basis of the 1871 Census, which includes three variables that arguably predict dissident behavior: religion, age, and education. Specifically, one might expect that protests are more likely in young, Protestant, more educated communities. Reassuringly, Table 2 shows that the variables do not predict the corruption of priests. In a final step, we also use the panel data on secret police officers (discussed above) and explore whether the number of officers before 1949 predicts the corruption of priests.

\footnotetext{
${ }^{9}$ Details on the data construction are provided in Online Appendix A.4.
} 
Here, too, Table 2 shows a null effect. The presence of secret police officers does not explain the corruption of priests.

\section{Excludability}

Having argued that corrupted priests are exogenous, for the IV to work one must also assume that the presence of corrupted priests only affects protests by spurring the recruitment of additional spies. Three pieces of evidence make this assumption plausible. First, as laid out above, the regime used corrupted priests to covertly repress citizens. Overt spies-particularly priests-are not effective. The relative secrecy therefore rules out a number of backdoor paths such as backlash or disappointment with one's local priest. ${ }^{10}$ Second and related, the data on corrupted priests comes from the 1950s, while we observe protests in the 1980s. Any backdoor paths must thus be operating for a rather long period, which seems less likely. Third, a quantitative way to test whether corrupted priests affect protests via rivaling channels (not via surveillance, but, e.g., via indoctrination) is conducting a falsification test. We did so by collecting additional data on protests in the neighboring region of Lower Silesia. In Table A.15 in the Online Appendix, we show that protests in this region are entirely unaffected by their closeness to areas in Upper Silesia with corrupted priests. This is reassuring because were there such a correlation it would be due to a backdoor path because the main channel (spy recruitment) did not take place in this region.

\section{Results}

In Table 3, we estimate a two-stage least-squares IV regression, where we instrument the presence of secret police officers with corrupted priests. The results confirm the headline findings from above. Again, we find that surveillance sparks protests but reduces sabotage, even when including region fixed effects. All estimates are substantively meaningful and highly significant.

\section{Robustness}

We briefly introduce two additional robustness tests for the IV model, which we detail in Online Appendix A.6. A first robustness test in Table A.13 demonstrates that results are highly similar when focusing on priests who were relocated by the Church after they started spying (thus alleviating concerns about endogeneity). A second robustness test in Table A.14 makes use of data on compromising information, which we were able to gather for 57 priests. Based on this data we construct an alternative IV variable (Kompromat), which more credibly captures "exogenously" corrupted priests, and show that results are robust.

\footnotetext{
${ }^{10}$ Nalepa and Pop-Eleches (2019) show that the infiltration of the Catholic Church remained undetected even after the "patriot priest" campaign came to an end.
}

\section{TABLE 2. Predicting Corrupted Priests with Pretreatment Data}

\begin{tabular}{|c|c|}
\hline & Corrupted priests \\
\hline & (1) \\
\hline Russian occupation & $\begin{array}{l}-0.013 \\
(0.023)\end{array}$ \\
\hline Industrialization & $\begin{array}{c}0.006 \\
(0.026)\end{array}$ \\
\hline Coal deposits & $\begin{array}{c}0.014 \\
(0.024)\end{array}$ \\
\hline Protests (40s) & $\begin{array}{c}0.037 \\
(0.028)\end{array}$ \\
\hline Sabotage (40s) & $\begin{array}{c}0.009 \\
(0.041)\end{array}$ \\
\hline Terror (40s) & $\begin{array}{c}0.047 \\
(0.025)\end{array}$ \\
\hline Jews \% (1871) & $\begin{array}{c}0.011 \\
(0.028)\end{array}$ \\
\hline Men \% (1871) & $\begin{array}{c}0.061 \\
(0.048)\end{array}$ \\
\hline Women \% (1871) & $\begin{array}{l}-0.042 \\
(0.078)\end{array}$ \\
\hline Protestants \% (1871) & $\begin{array}{c}0.011 \\
(0.105)\end{array}$ \\
\hline Catholics \% (1871) & $\begin{array}{c}0.054 \\
(0.110)\end{array}$ \\
\hline Other Christian \% (1871) & $\begin{array}{l}-0.025 \\
(0.035)\end{array}$ \\
\hline Other religion \% (1871) & $\begin{array}{c}0.097 \\
(0.065)\end{array}$ \\
\hline Age under $10 \%$ (1871) & $\begin{array}{l}-0.003 \\
(0.090)\end{array}$ \\
\hline Literate \% (1871) & $\begin{array}{c}0.029 \\
(0.120)\end{array}$ \\
\hline No school \% (1871) & $\begin{array}{l}-0.035 \\
(0.038)\end{array}$ \\
\hline Illiterate \% (1871) & $\begin{array}{l}-0.028 \\
(0.088)\end{array}$ \\
\hline Secret police officers (1945) & $\begin{array}{c}0.107 \\
(0.299)\end{array}$ \\
\hline Secret police officers (1946) & $\begin{array}{c}0.508 \\
(0.537)\end{array}$ \\
\hline Secret police officers (1947) & $\begin{array}{l}-0.690 \\
(1.081)\end{array}$ \\
\hline Secret police officers (1948) & $\begin{array}{c}0.119 \\
(0.920)\end{array}$ \\
\hline $\begin{array}{l}N \\
\text { Adjusted } R^{2}\end{array}$ & $\begin{array}{l}297 \\
0.090\end{array}$ \\
\hline
\end{tabular}

\section{MECHANISMS}

Why does surveillance correlate with more protests and less sabotage? In the theoretical section, we proposed two channels that imply a positive effect of surveillance on protests: surveillance creates anger as well as an incentive to reveal one's true loyalties. The two 
TABLE 3. Effect of Surveillance on Resistance (IV)

\begin{tabular}{|c|c|c|c|c|}
\hline & \multicolumn{2}{|c|}{ Protests } & \multicolumn{2}{|c|}{ Sabotage } \\
\hline & (1) & (2) & (3) & (4) \\
\hline Surveillance & $\begin{array}{c}0.177^{\star \star \star} \\
(0.021)\end{array}$ & $\begin{array}{c}0.154^{\star \star \star} \\
(0.018)\end{array}$ & $\begin{array}{c}-0.161^{\star \star \star} \\
(0.019)\end{array}$ & $\begin{array}{c}-0.128^{\star \star *} \\
(0.013)\end{array}$ \\
\hline Controls & No & Yes & No & Yes \\
\hline FEs & No & Yes & No & Yes \\
\hline$N$ & 297 & 216 & 234 & 206 \\
\hline Adjusted $R^{2}$ & 0.387 & 0.166 & 0.006 & 0.196 \\
\hline
\end{tabular}

channels, however, also predicted an increase in sabotage, which we do not observe. To make sense of this finding, we conducted 20 semistructured interviews, collected 62 testimonies of dissidents, and drew on historical case studies (details on the data, including Institutional Review Board approval, are provided in Online Appendix A.7). We use this data to trace the causal mechanisms through which surveillance affected resistance in our context. We begin with the positive effect of surveillance on protests, before turning to the negative effect on sabotage.

\section{Why Did Surveillance Increase Protests?}

\section{Individual Level: Surveillance Causes Anger}

In the theoretical section, we hypothesized that physical surveillance can create anger and thus spark protests. In our own interviews, several respondents confirmed that anger was a core emotion felt when faced with secret police surveillance. Dissident Michał Luty, for example, recalls "I was just getting ready to leave the house when I heard the doorbell. After looking out at the corridor, I saw two security officers I knew, to whom my neighbor was opening the door. [...] I was angry, all the more so as [...] I couldn't do anything, not even tell anyone about the event." Another interviewee remembered that surveillance led to "neurotic symptoms" among their relatives and friends, including heightened aggressiveness in interpersonal relations. Dissident Leopold Tyrmand, minutes after learning that he had been surveilled, described his anger toward the secret police as follows: "I felt crushed, sweaty, full of anger [...]. I felt treated inhumanely by those dull, lousy, brutal people, maybe cunning and clever, but actually fools. There was a suspicious contempt in their gazes [...], contempt for my powerlessness, for my inability to throw the same gaze at them," highlighting the anger he felt toward the invisible enemy (Tyrmand 1983,174). Indeed, across all 62 dissident testimonies we analyzed, the most salient emotion mentioned in the context of surveillancerelated terms is "wściekły" (angry/mad) - a conclusion we arrived at by applying natural language processing to the testimonies (see Online Appendix A.10 for details).
Did anger, in turn, cause protests? Two of our interviewees explicitly stated that the state of anger allowed them to overcome the fear typically associated with repression. Discussing student protests at the Silesian University of Technology, Barbara Kozłowska notes that students were so angry at the secret police that they were ready to fight them at any time. During student meetings, Kozłowska recalls, "we removed legs from the chairs and prepared them as weapons in case of a possible fight" (IPN, Katowice, Sign. 030/222). Evidence for the link from anger to protests can also be gleaned from the antiregime uprisings that shook Poland in the early days of the regime. In 1956, Nikita Khrushchev, the first secretary of the Communist Party of the Soviet Union, delivered a famous speech revealing crimes of the Stalinist regime. Across the Eastern Block, the report opened citizens' eyes to the scale of secret police surveillance and created widespread anger. In Poland, the revelations led to the first massive wave of antiregime protests between June and December 1956. In Poznań, for instance, workers from a brick factory stormed law enforcement facilities, including prisons, and liberated hundreds of inmates..$^{11}$ Another example of how anger, sparked by surveillance, caused protests comes from the testimony of Lech Osiak. A long-time Communist party member, Osiak joined Solidarność in 1980 in the Katowice steelworks. When other union members discovered Osiak's connections with the repressive apparatus, a fullfledged "rebellion" erupted in the company. Osiak was barely "saved from the anger of the crew" by a colleague who helped him out of the building. ${ }^{12}$

\section{Group Level: Surveillance Incentivizes Truthful Revelation of Loyalties}

In the theoretical section, we also hypothesized that physical surveillance creates incentives to reveal one's true loyalties, thus facilitating collective action. A lucid example for this channel is found in the testimony of a Solidarność leader at the Katowice Steelworks. One

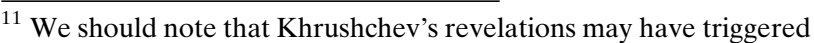
protests not only because of anger about the scale of surveillance but also because it signaled widening political opportunities.

${ }^{12}$ Archival interview with Lech Osiak, 12/12/2004.
} 
day, the newly established leader was asked to meet the company's management, to which other union members reacted with suspicion. One interviewee clarified that at the time, "any new employee close to the trade union was immediately suspected of being an SB plug." To counter mounting rumors, the leader decided to publicly demand the resignation of the Communist Party's management, revealing the scale of mismanagement of the company. He felt that only by starting an open conflict with the company's leadership could he credibly signal to his colleagues that he was not a regime collaborator. Such costly signals were also demanded by opposition groups, including Solidarność, of new joiners in an attempt to separate truly committed members from bystanders or regime agents. An example comes from the biography of dissident Kazimierz Świtoń. In 1977, Świtoń joined a Catholic society based at St. Martin's Church in Katowice. Unbeknownst to Świton, the society was home to a prominent opposition group. Świton was therefore immediately suspected of being a regime agent. To gain trust, the group asked Świton to participate in a public hunger strike. Świtoń agreed and was then allowed into the group.

Another example for the need to truthfully signal one's loyalties is the case of Stanisław Lem, the author of the famous Solaris novel. In the 1950s, the secret police began surveilling Lem. The officers learned about Lem's early writings, which allegedly derided the regime. The interactions between Lem and the secret police, in turn, led to rumors that Lem himself was a regime agent. Lem's long-time mentor, Michał Choynowski, therefore cut ties with the writer, falsely suspecting Lem of being a spy (Orliński 2017,122). Being wrongly accused of spying created a pronounced strain on Lem's social relations. To regain his reputation, Lem began to openly defy the government. In 1953, for instance, Lem refused to mourn Stalin's death, "celebrating" the occasion by going on vacation with his friends.

Did the revelation of loyalties, in turn, drive antiregime protests? Evidence for this link can be found in the memoirs of Jan Jurkiewicz, a key opposition figure in Katowice. Recalling his engagement in antiregime protests at the university, Jurkiewicz recalls, "We knew, of course, that there was a police force, but [...] we thought that if we decided to officially voice concerns, if we spoke out in public, if our names were displayed on notice boards, it would be difficult to conspire against us" (IPN, Katowice, Sign. 0103/138, vol. 5). Jurkiewicz and his Independent Students' Association (NZS, Polish acronym) believed that the transparency of their resistance shielded them against the risks of infiltration by the secret police and facilitated the ongoing protests. Moreover, being openly defiant toward the regime helped NZS members signal their true loyalties to other bystanders, encouraging the latter to join in. Secret police briefs from the period acknowledge that this "transparency strategy" effectively led to a loss of importance of secret informants within the SB surveillance networks at the university and a considerable drop in their denunciation notes (Kurpierz 2012, 89-91). A second example comes from the above-mentioned union leader in the Katowice Steelworks who was distrusted by his colleagues and publicly demanded the resignation of the Communist Party's management of the company. His revelation of the mismanagement - that is, his decision to publicly reveal his true loyalties - contributed to the large-scale protests in the company. These protests, in turn, led to the establishment of a prominent Solidarność figure as a new director.

\section{Why Did Surveillance Reduce Sabotage?}

\section{Individual Level: Surveillance and Fear}

In the theoretical section, we proposed one mechanism that links physical surveillance to decreased individuallevel resistance: fear. Some archival testimonies, indeed, point to instances where surveillance instilled fear. For example, former dissident Janusz Wiśniewski was described by his friends as a "man who was paralyzed by fear and stopped working for the union completely" after his first encounters with the secret police. ${ }^{13}$ Surveillance also created fear of social discreditation, especially among people involved in sabotage. The regime was known to portray saboteurs as morally corrupt, trying to damage their reputation among family, friends, and the larger public. The tactic was employed, for example, against steel workers in Katowice. Andrzej Rozpłochowski recalls that shirking workers who came to work late, neglected their duties, and falsified signatures on presence lists were accused of "alcohol libations, sexual orgies and the embezzlement of money." 14 This and similar incidences undoubtedly led some citizens to refrain from sabotage because surveillance made them fearful.

However, three pieces of evidence cast doubt on the individual-level fear mechanism as a consistent explanation for the observed negative effect of surveillance on sabotage. First, our own interviewees did not point to fear, nor was the variable a significant predictor in the text analysis (see Online Appendix Section A.10). Second, the negative correlation between surveillance and sabotage is also detectable in municipalities where secret police officers were not instructed to monitor sabotage (see Table A.20 in the Online Appendix). Third, if surveillance sparked anger-as we showed above-it is difficult to understand why a less risky form of resistance, sabotage, would go down, at least if the resistance tactics were undertaken by the same citizens for which we provide evidence momentarily.

\section{Group Level: Why Protesters Do Not Engage in Sabotage}

What other mechanism, then, links surveillance to reduced sabotage? Based on our qualitative evidence from Upper Silesia, we uncovered a third mechanism, which is intricately linked to protest dynamics.

\footnotetext{
${ }^{13}$ Archival interview with Włodzimierz Kapczyński between 2004 and 2005.

${ }^{14}$ Archival interview on $02 / 09 / 2005$.
} 
Authoritarian regimes facing unrest are known to frame protesters as provocateurs. This strategy has two goals. First, it disincentivizes bystanders from joining the protests. Second, it gives the government a pretext to violently oppose the uprising (Moore 2000). It is for these two reasons that authoritarian regimes are known to infiltrate protest movements and push protesters to become rowdy and violent. Protesters therefore have a strong incentive to avoid being displayed as corrupt and abstain from sabotage and other forms of welfare destruction..$^{15}$ As Vaclav Havel in his famous essay The Power of the Powerless writes, "dissident groups [need to] operate publicly and openly, insisting not only that their activity is in line with the law, but that achieving respect for the law is one of their main aims" (Havel and Wilson 1985, 51).

Several historic examples from Upper Silesia and beyond support the observation that protesters refrained from sabotage to give the government no reason to violently intervene. In 1970, for example, the members of a strike committee in the Gdańsk shipyard prevented dissidents from leaving the protest venue and going into town. The organizers were afraid that this would lead to rioting and property destruction and that the protest would then be violently quelled by the regime (Cenckiewicz 2003, 287). In Upper Silesia, protesters at the university in Katowice banned any individuals who were drunk; the conduct of the protesters was "taken very seriously," remembers Jan Jurkiwiecz (Kurpierz 2012, 187). Solidarność chapters, too, engaged in strict workplace policing. The aforementioned dissident Kazimierz Świton, for example, recalls that the union leaders "always pointed out to the young union members that if they want to have fun or drink something [alcohol], they have to do it in a more suitable place [in order] not to provide water for the SB-mill." ${ }^{16}$ For this very reason, dissident groups chose workplaces as suitable venues for protests rather than open spaces where sabotage was harder to prevent. Dissident Andrzej Gwiazda explains this choice as follows: "In our manual it was written that strikes should be occupational. During the strike, the crew was to take over the responsibility for the plant; there was an obligation to set up a strike guard; one should make sure that there is no sabotage, theft, or damage."17

What is more, our qualitative interviews revealed direct evidence that Solidarność leaders actively sought to ensure a high level of compliance with Saturday work (Subbotnik). As already mentioned, Subbotniks were organized to clean the streets, build schools and

\footnotetext{
${ }^{15}$ One concern related to this interpretation of our quantitative findings is that our outcomes-protests and sabotage-were measured at different points in time. To address this issue, we digitized data on protests from the 1970s in order to show that (i) they strongly predict protests in the 1980s (see Table A.16 in the Online Appendix) and (ii) that they also correlate positively with surveillance (Table A.17). We cannot, however, use the protest data from the 1970s in the primary analysis, as it has incomplete coverage (see Online Appendix A.9).

${ }^{16}$ Archival interview on $02 / 25 / 2005$.

${ }^{17}$ Archival interview between $12 / 2004$ and 01/2005.
}

factories, fix public infrastructure, and other community services. Sabotage during subbotnik, therefore, could have been interpreted as free-riding and damage committed against the public. For this reason, Solidarność leaders were careful to monitor the behavior of their members during Subbotniks. They were in a privileged position to do so insofar as Subbotniks were typically organized through workplaces and trade unions knew who was supposed to do what and when.

The need to refrain from sabotage for the sake of successful public resistance is also conveyed in the very name of Solidarność. According to popular belief, the name refers to solidarity (solidarność in Polish) among workers who unite to fight for a common goal despite manifold particular interests. Yet, Krzysztof Wyszkowski, the creator of the movement's name, explains that the original references for the name were quite different: Besides the obvious "solidarity," Solidarność also refers to "(prewar) solidity" (solidny in Polish) and "enlightenment" (sol in Latin). These connotations, according to Wyszkowski, conveyed the need of the movement to oppose the regime with dignity, refraining from using ad hoc and unreliable "half measures" such as sabotage. Had such tactics been used, he feared, the regime could easily have belittled the movement to "brawls calling for the re-employment of undisciplined shipyard workers." 18

What quantitative evidence is there for the proposed causal mechanism? First, if the reduction in sabotage is the result of protest policing, one would arguably expect Solidarność members to be less likely to engage in sabotage. To test this conjecture, we make use of an individual-level survey collected in 1988 (Polish Panel Survey). In line with the substitution mechanism, we find that respondents who report being members of a trade union are less likely to report engaging in economic noncompliance (see Table A.19 in the Online Appendix). Second, if citizens reduced sabotage in order to avoid being portrayed as corrupt, the reduction in sabotage should be particularly pronounced in areas with greater Solidarność organizational capacity. Evidence for this conjecture is provided in Table A.21, which confirms that sabotage is significantly lower in areas that have Solidarność regional delegates (a proxy for the strength of local organizational capacity).

\section{GENERALIZABILITY}

\section{Scope Conditions}

The stipulated model regarding the positive effect of surveillance on protests (and the subsequent negative effect on sabotage) hinges critically on the nature of surveillance. Based on our qualitative data, we distilled three important scope conditions that arguably need to be in place in order for surveillance to spark protests: surveillance must be relatively (i) overt, (ii) comprehensive, and (iii) continuous. We discuss

\footnotetext{
${ }^{18}$ Interview with Krzysztof Wyszkowski on 02/16/2018
} 
the qualitative evidence for these scope conditions in turn.

\section{Openness}

A first scope condition for surveillance to create both anger and an incentive to reveal one's loyalties was the relatively open manner with which surveillance was conducted in the PPR. As one of our interviewees recalled, "[the secret police] tried to "conspire their surveillance,' but they did it poorly." 19 First, the relative openness of surveillance in Upper Silesia was crucial for anger to set in. A case in point is provided by Wojtek Jedrzejas who, in 1989, spotted an agent who was trying to stealthily take pictures during a conference at a local polytechnic. The discovery of the agent angered students who then "escorted" the agent to the door (Kurpierz 2012, 333). Had the act of surveillance not been revealed, there would have been no reason for or target of anger. Second, the relative openness of surveillance in Upper Silesia was also necessary to set in motion the loyalty revelation channel. During the same instance, Jedrzejas recalls that he gave the agent "a card with names and pictures of all members of the local NZS" before throwing him out, thus revealing everyone's loyalties (Kurpierz 2012, 333). Had surveillance been fully concealed, there would have been no clear way to separate oneself from the secret police.

\section{Comprehensiveness}

A second scope condition for surveillance to set the anger and loyalty revelation channels into action was the relatively comprehensive nature of surveillance in the PPR. Rather than exclusively target core dissident activities, the Polish regime pursued a sweeping surveillance strategy, which one interviewee labeled as the most extreme "deprivation of liberties." First, surveillance's comprehensive nature reinforced anger. Leopold Tyrmand recalls that agents "even knew which of my eleven underpants I liked most," which made him "full of disgust" (Tyrmand 1983, 156). Second, surveillance's comprehensiveness reinforced incentives to reveal one's true loyalties. Kazimierz Świton recalls that the sweeping nature of surveillance "put him into a state of mental and nervous breakdown, making him argue with his neighbors, closest family members and friends." ${ }^{20}$ One way to escape surveillance and the repercussions for Świton's personal life was to signal his true loyalties to friends and family by going on the aforementioned hunger strike (Kobylańska and Miśkiewicz 2008).

\section{Continuity}

A third, related scope condition for surveillance to activate the anger and loyalty revelation channels was the enduring nature of surveillance. The regime, rather than crank down during tough times, engaged in

\footnotetext{
${ }^{19}$ Own interview on 12/21/2020.

${ }^{20}$ Archival interview with Kazimierz Świtoń on 02/24/2004.
}

continuous surveillance. First, the lasting nature of surveillance sparked real anger since there was no end in sight. A case in point is Zdzisław Mnich, a trade union leader in Bielsko-Biała who was surveilled for over a decade. When the searches were accidentally discovered, Mnich reacted with anger and outrage. Mnich realized that no matter how he acted, he would always be surveilled. Second, the continuity of surveillance arguably reinforced incentives to reveal one's true loyalties. Indeed, Mnich reacted to the lasting surveillance by distributing antisocialist publications and leaflets, partly so as to signal he was not part of the secret police who took him in for questioning after the searches went public.

\section{External Validity}

How does the PPR's use of surveillance compare with other regime's use of this method of repression? While providing a conclusive answer is beyond the scope of this study, we tackle this question by using the U.S. Department of State's (DoS) Country Reports on Human Rights, which provide a comprehensive view of repression around the globe. ${ }^{21}$ As we detail in Online Appendix A.11, we use these reports to classify surveillance in 202 countries between 1979 to 2014. Specifically, we apply natural language processing to the over 20,000 pages of text to assess to what degree surveillance is commonly described as (i) open, (ii) comprehensive, and (iii) continuous and how it compares with other common types of repression. Figure A4 shows that around the globe, the DoS describes surveillance, on average, in such terms. Taken together, the PPR's use of surveillance, therefore, does not strike us as highly unusual. What is more, we also merged the DoS country reports with protest data and constructed a country-year panel, covering the period between 1981 and 1986 (coinciding with the period of our main analysis; see Online Appendix A.11). The analysis, shown in Figure A3 and Table A.22, confirms a positive correlation between surveillance and protests, thus underlining the generalizability of our finding from Poland. And, as shown in Table A.23, the positive correlation is also detectable when using conflict and surveillance data from 2019.

\section{CONCLUSION}

This paper has revisited the vexed relationship between state repression and resistance. Our empirical focus was on physical surveillance in Communist Poland. Drawing on decades of formerly classified data on surveillance by the Polish secret police in the Upper Silesia region, we found that surveillance sparked antiregime protests by creating widespread anger as well as by providing citizens with an incentive to reveal their true loyalties, thus facilitating collective action. At the same time, surveillance also reduced sabotage because, once on the streets,

\footnotetext{
${ }^{21} \mathrm{We}$ are indebted to Christopher Fariss for making these data available to us.
} 
dissidents had a good reason to avoid being displayed as corrupt and thus abstained from sabotage and other forms of welfare destruction.

Before concluding, we want to briefly reflect on the implications of our historic case study for today's world. A first salient question is whether traditional, in-person surveillance can inform our understanding of modern (digital) surveillance. Drawing on the aforementioned scope conditions, one may expect digital surveillance to be a less likely driver of antiregime resistance for three reasons. First, digital surveillance is arguably more covert than traditional forms of physical surveillance. Citizens may therefore harbor less anger against the regime, given that the enemy is invisible. Second, digital surveillance is confined to the digital realm and thus arguably less comprehensive than physical surveillance, at least as practiced in Poland. Citizens can therefore escape digital surveillance more easily, e.g., by staying offline. Third, digital surveillance does not rely on the use of informants. As a result, it does not create similar levels of mistrust within communities, which is a crucial precondition to incentivize the revelation of dissidents' loyalties. That said, digital surveillance may be a more (cost-)effective way to raise the transaction costs of antiregime resistance, at least when compared with wiretapping, eavesdropping, or the use and management of informants. We must caution, however, that these considerations are speculative, though they underscore the necessity of comparing different forms of surveillance practices.

A second question concerns the specificity of the Polish case and, in particular, the existence of Solidarność. The translation of anger into collective action is no trivial task. Our evidence implies that Solidarność was well placed to take up the task of turning anger into collective action for two key reasons. First, Solidarność was a newly established, bottom-up coalition of trade unions without clear central leadership, at least in the beginning. The union was therefore in an ideal position to turn citizens' mounting anger into sustained antiregime collective action by organizing spontaneous, partly improvised protests. A more formalized organization with rigid hierarchies might not have been able to act locally and quickly enough to capitalize on citizens' anger (which tends to be unpredictable and short lived). Andrzej Gwiazda, for instance, underlined Solidarnośćs spontaneity as one of its greatest strengths: "How was the strike organized? I don't know how much it was organized [...]; everything indicates that it did not go according to any plan. It was simply such a peculiar time that the right people were in the right place." 22 Second, the fact that Solidarność was a new organization facilitated its role in encouraging the revelation of citizens' true loyalties, which further boosted antiregime collective action. An old organization-like the Catholic Church - would not have been able to screen prospective members depending on their willingness to publicly express dissent because most citizens were already part of it.

\footnotetext{
${ }^{22}$ Archival interview 12/2004 and 01/2005.
}

More broadly, these considerations underline the important role that the larger political opportunity structure in Poland in the 1970s and 80s played in channeling anger into protest. Absent Solidarność, anger (partly sparked by surveillance) may only have led to a few spontaneous protests - as was the case in the 1970s (Kenney 1997). It was not until the 1980s, however, that anger and the eventual protests were translated into a broader social movement. As stated, Solidarność was able to do so, arguably, because it was a new, decentralized organization of workers, which was able not only to channel anger and facilitate preference revelation but also to ensure the legality of protests within industrial sites. A careful analysis of these variables - institutional novelty and decentralization - was beyond the scope of our study because we studied one case and thus lacked variation. We believe, however, that future scholarship could revisit these conditions, perhaps by comparing the centrality and novelty of existing civil society organizations in a systematic manner across authoritarian regimes. Such research could also complement and revisit our tentative evidence pointing to cross-country correlations between surveillance and protests.

\section{SUPPLEMENTARY MATERIALS}

To view supplementary material for this article, please visit http://doi.org/10.1017/S0003055421000770.

\section{DATA AVAILABILITY STATEMENT}

The data, code, and any additional materials required to replicate all analyses in this article are available at the American Political Science Review Dataverse: https://doi.org/10.7910/DVN/JWTRSC.

\section{ACKNOWLEDGMENTS}

The authors are grateful to Monika Nalepa, Joanna Lewandowska, Przemysław Miśkiewicz, and Christopher Fariss for help in accessing data sources. Joanna Boduszyńska, Wojciech Boduszyński, Katharina Duerrmeier, Ewelina Niemczyk, and Till Tietz provided superb research assistance. The authors would also like to thank Volha Charnysh, Elias Dinas, Ester Driel, Felix Elwert, Diego Gambetta, Anita Gohdes, Edoardo Grillo, Sebastian Hellmeier, Egor Lazarev, Philipp Lutscher, Kasia Nalewajko, Max Schaub, Aron Szekely, Vicente Valentim, Erin York, and Lukas Zidella, as well as seminar participants at the Historical Political Economy Workshop at Cornell University, the University of Gothenburg, the ifo institute of economic research, Hitotsubashi University, the IPERG at the University of Barcelona, and the University of Bern for superb feedback. The authors are listed alphabetically. 


\section{REFERENCES}

Balcells, Laia, Spencer Dorsey, and Juan Tellez. 2020. "Repression and Dissent in Contemporary Catalonia." British Journal of Political Science. doi:10.1017/S0007123420000307.

Blaydes, Lisa. 2018. State of Repression: Iraq under Saddam Hussein. Princeton, NJ: Princeton University Press.

Brockett, Charles D. 1993. "A Protest-Cycle Resolution of the Repression/Popular-Protest Paradox." Social Science History 17 (3): 457-84.

Carey, Sabine C. 2006. "The Dynamic Relationship between Protest and Repression." Political Research Quarterly 59 (1): 1-11.

Cenckiewicz, Sławomir. 2003. "Grudzien '70 w Gdańsku według tajnych współpracowników Służby Bezpieczeństa.” Pamieć $i$ Sprawiedliwość 1 (3): 275-301.

Cunningham, David. 2003. "The Patterning of Repression: FBI Counterintelligence and the New Left." Social Forces 82 (1):209-40.

Davenport, Christian. 2005. "Understanding Covert Repressive Action: The Case of the US Government against the Republic of New Africa." Journal of Conflict Resolution 49 (1): 120-40.

Della Porta, Donatella. 2006. Social Movements, Political Violence, and the State: A Comparative Analysis of Italy and Germany. Cambridge: Cambridge University Press.

Donner, Frank J. 1980. The Age of Surveillance: The Aims and Methods of America's Political Intelligence System. New York: Vintage.

Earl, Jennifer. 2011. "Political Repression: Iron Fists, Velvet Gloves, and Diffuse Control." Annual Review of Sociology 37: 261-84.

Einwohner, Rachel L. 2003. "Opportunity, Honor, and Action in the Warsaw Ghetto Uprising of 1943." American Journal of Sociology 109 (3): 650-75.

Fariss, Christopher J. 2019. "Yes, Human Rights Practices Are Improving over Time." The American Political Science Review 113 (3): 868-81.

Fuchs, Christian. 2013. "Political Economy and Surveillance Theory." Critical Sociology 39 (5): 671-87.

Gläßel, Christian, and Katrin Paula. 2019. "Sometimes Less Is More: Censorship, News Falsification, and Disapproval in 1989 East Germany." American Journal of Political Science 64 (3): 682-98.

Gohdes, Anita R. 2020. "Repression Technology: Internet Accessibility and State Violence." American Journal of Political Science 64 (3): 488-503.

Gross, Jan Tomasz. 2002. Revolution from Abroad: The Soviet Conquest of Poland's Western Ukraine and Western Belorussia. Princeton, NJ: Princeton University Press.

Gurr, Ted Robert. 1970. Why Men Rebel. Boulder, CO: Paradigm Publishers.

Hager, Anselm, Krzysztof Krakowski, and Max Schaub. 2019. "Ethnic Riots and Prosocial Behavior: Evidence from Kyrgyzstan.” American Political Science Review 113 (4): 1029-44.

Hager, Anselm, and Krzysztof Krakowski. 2021. "Replication Data for: Does State Repression Spark Protests? Evidence from Secret Police Surveillance in Communist Poland." Harvard Dataverse. Dataset. https://doi.org/10.7910/DVN/JWTRSC.

Havel, Vaclav, and Paul Wilson. 1985. "The Power of the Powerless." International Journal of Politics 15 (3-4): 23-96.

Kenney, Padraic. 1997. Rebuilding Poland: Workers and Communists, 1945-1950. Ithaca, NY: Cornell University Press.

King, Gary, Jennifer Pan, and Margaret E. Roberts. 2013. "How Censorship in China Allows Government Criticism but Silences Collective Expression." American Political Science Review 107 (2): 326-43.

Kobylańska, Monika, and Przemysław Miśkiewicz. 2008. "Najniebezpieczniejsza rodzina na Ślasku." Onet Wiadomości, May 6. https://wiadomosci.onet.pl/kiosk/najniebezpieczniejszarodzina-na-slasku/4c612.

Kuran, Timur. 1997. Private Truths, Public Lies. Cambridge, MA: Harvard University Press.
Kurpierz, Tomasz. 2012. Zbuntowani. Niezależne Zrzeszenie Studentów w Wojewødztwie Katowickim 1980-1989. Katowice, PL: Instytut Pamieć i Narodowej.

Lewandowska, Joanna. 2021. II Krajowy Zjazd Delegatów NSZZ "Solidarność" - koniec i poczatek. Gdańsk, PL: Archiwum Historyczne Komisji Krajowej NSZZ Solidarność.

Lichbach, Mark Irving. 1987. "Deterrence or Escalation? The Puzzle of Aggregate Studies of Repression and Dissent." Journal of Conflict Resolution 31 (2): 266-97.

Lichter, Andreas, Max Löffler, and Sebastian Siegloch. 2021. "The Long-Term Costs of Government Surveillance: Insights from Stasi Spying in East Germany." Journal of the European Economic Association 19 (2): 741-89.

Loveman, Mara. 1998. "High-Risk Collective Action: Defending Human Rights in Chile, Uruguay, and Argentina." American Journal of Sociology 104 (2): 477-525.

Lyon, David. 2007. Surveillance Studies: An Overview. Cambridge: Polity.

Marx, Gary T. 1988. Undercover: Police Surveillance in America. Oakland: University of California Press.

Moore, Will H. 2000. "The Repression of Dissent: A Substitution Model of Government Coercion." Journal of Conflict Resolution 44 (1): 107-27.

Nalepa, Monika, and Grigore Pop-Eleches. 2019. "Authoritarian Institutional Infiltration: Causes and Consequences." Working Paper.

Orliński, Wojciech. 2017. Lem. Życie nie z tej ziemi. Wołowiec, PL: Wydawnictwo Agora.

Parkinson, Sarah Elizabeth. 2013. "Organizing Rebellion: Rethinking High-Risk Mobilization and Social Networks in War." American Political Science Review 107 (3): 418-32.

Rozenas, Arturas, Sebastian Schutte, and Yuri Zhukov. 2017. "The Political Legacy of Violence: The Long-Term Impact of Stalin's Repression in Ukraine." The Journal of Politics 79 (4): 1147-61.

Scott, James C. 1985. Weapons of the Weak: Everyday Forms of Peasant Resistance. New Haven, CT: Yale University Press.

Scott, James C. 1989. "Everyday Forms of Resistance." The Copenhagen Journal of Asian Studies 4: 33-62.

Shelley, Louise I. 1996. Policing Soviet Society: The Evolution of State Control. London: Routledge.

Staar, Richard F. 1956. "The Church of Silence in Communist Poland." The Catholic Historical Review 42 (3): 296-321.

Starr, Amory, Luis A. Fernandez, Randall Amster, Lesley J. Wood, and Manuel J. Caro. 2008. "The Impacts of State Surveillance on Political Assembly and Association: A Socio-Legal Analysis." Qualitative Sociology 31 (3): 251-70.

Sullivan, Christopher M. 2016. "Political Repression and the Destruction of Dissident Organizations: Evidence from the Archives of the Guatemalan National Police." World Politics 68 (4): 645-76.

Thompson, Beverly Yuen. 2007. "The Global Justice Movement's Use of 'Jail Solidarity' as a Response to Police Repression and Arrest: An Ethnographic Study." Qualitative Inquiry 13 (1): 141-59.

Truex, Rory. 2019. "Focal Points, Dissident Calendars, and Preemptive Repression." Journal of Conflict Resolution 63 (4): 1032-52.

Tyrmand, Leopold. 1983. Dziennik 1954. Warszawa, PL: Res Publica.

$\mathrm{Xu}, \mathrm{Xu}$. 2020. "To Repress or to Co-Opt? Authoritarian Control in the Age of Digital Surveillance." American Journal of Political Science 65 (2): 309-25.

Young, Lauren E. 2019. "The Psychology of State Repression: Fear and Dissent Decisions in Zimbabwe." American Political Science Review 113 (1): 140-55.

Zhukov, Yuri. 2019. "Repression 'Works' (Just Not in Moderation)." Unpublished Working Paper.

Żurek, Jacek. 2009. Ruch "Ksieży Patriotów" w województwie katowickim w latach 1949-1956. Katowice, PL: Instytut Pamieć i Narodowej. 